SB 341

.N8

Copy 1
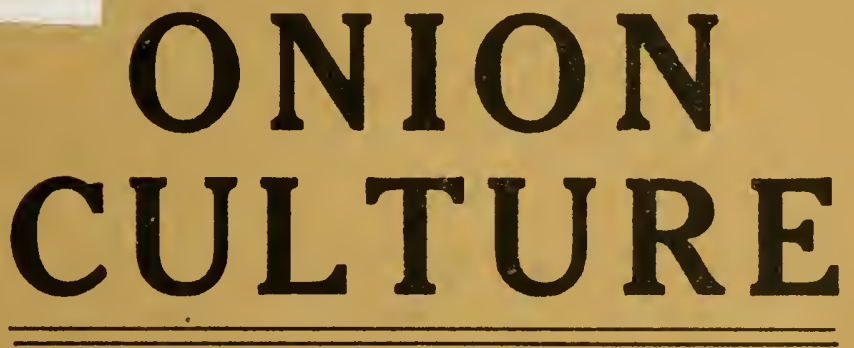

ㅁ.

口

口

口

NORTHRUP, KING \& CO. SEEDSMEN

MINNEAPOLIS - - MINNESOTA 


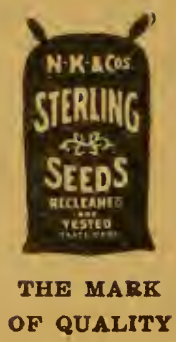

$\because \vdots:$ 


\section{ONION CULTURE}

PLANTING, CULTIVATING HARVESTING AND MARKETING

PRICE TEN CENTS

NORTHRUP, KING \& CO. MINNEAPOLIS - _ - MINNESOTA 
Copyright 1915

by

Northrup, King \& Co.

$\because \vdots:$

MAR -81915

C.CIA:395681 


\section{Foreword.}

$7 \mathrm{HE}$ growing of Onions has been a stepping stone, in many instances, to the making of a home and an independent farmer. A few acres devoted to this industry will return a handsome income to the man or boy who will carefully test the possibilities of his soil in yields and the markets for high qualities.

This booklet attempts to answer in a practical manner the many questions that arise in the mind of the prospective grower. This is not a cyclopedia on Onion Culture, but we believe it will prove helpful to many who are seeking information on the subject with no disposition to be severely critical. The proposition is not presented as a short cut to wealth, but a means of earning an independent living.

Poultry farming and small fruits may supplement Onion growing for additional income. However, everyone admires the specialist who firmly resolves to succeed in one chosen undertaking, making it a life work, and thus prepares himself with books, study, observation, experience, etc., to excel. An educated head must supplement a skillful hand to do 20th century falming. 


\section{ONION CULTURE.}

The growing of Onions for a garden crop, and in a commercial way, is now engaging the attention of many farmers all over the United States. A garden, no matter how small, is not considered complete until it is stocked with Onions to be grown from sets of various kinds as well as a crop trom seed which will produce bulbs of several colors and shapes.

The United States produces many million bushels of Onions every year. However, there are hundreds of thousands of bushels imported to supply the demand. The stock that comes to us from abroad is mild in flavor and reaches this country when the markets are not well supplied and, as a result, prices are high. The South, Texas and California in particular, is now meeting the demand for early Onions, hence, imports are decreasing. The crop has become a staple in many sections where fields of 25 to 100 acres are grown on one farm.

The expense of growing, harvesting and marketing an acre of Onions may total two hundred dollars where hired help is employed. Onion culture recommends itself to the men who have small farms, where the price of land is high and where boys or women may be secured to do the hand weeding, thinning, harvesting, etc. Onions may be grown year after year on the same field provided the fertility is well maintained. Bulbs grown in the Northwest on new lands, especially in the timbered sections, have remarkably good quality, while the Red Globe variety is in especial demand for winter storage. These are grown in immense quantities for the purpose named and meet the shipping demands from the South and East. 


\section{SOIL SELECTION.}

Success or failure with a field of Onions will depend quite largely upon an intelligent selection of the soil, the lay of the land, and its physical condition. Onions thrive best on a rich sandy loam that is well drained, having a subsoil which will readily absorb surplus moisture and part with it when needed. Such soils occur in many localities in the Northwest, also in other parts of the United States, especially in the cut-over timber regions where small farms and large families are the rule.

We do not hesitate to recommend commercial Onion growing to these people because their soil is rich, free from weeds, full of humus and fertility -in fact, quite ideal for yields of 600 to 1,000 bushels per acre, which are possible under favorable conditions of soil and care. Heavy clay loans are not good for Onions until they are under-drained and made friable; or loose and springy, with clover growing and heavy dressings of barnyard manures. On account of the value of the crop and the expense of producing it, these items should be carefully considered before undertaking the growing of Onions as a specialty. We also advise growing a crop of potatoes or roots on the clover sod, which has previously been top dressed and pastured; or one crop of clover should be allowed to remain on the ground for added luumus and fertility.

\section{DRAINAGE.}

The drainage must be almost perfect to produce first class results. There should be no hollow places in the beds. On a sloping piece of land the dead furrows or alleys should be kept open. No crop of those usually grown in the market garden will give better returns for draining than will the Onion, but the time to drain is when the ground is being prepared, not after a heavy rain when water is standing in pools on the field.

Tile drains at frequent intervals, so placed that surplus water may readily escape from the soil are a decided ad- 
vantage in wet seasons. These are also used in times of extreme drought for sub-irrigation which may save a crop) from loss.

The ground thus selected and carefully prepared should be capable of producing $\$ 500$ worth of Onions per acre every year. There are many cases where a rather light sandy loam with a gravel subsoil may be made ready for profitable crops of Onions by preparing it as we have suggested, but, in spite of added humus and fertility, they are inclined to wash badly in the event of heavy rains and sutfer for the need of moisture when the weather is dry, hot and windy. Sandy lands tliat are not level sloould never be used for Onion culture because they will wash to such an extent that the crop will either be buried or stranded on the surface after heavy rains.

There are localities in Ohio, Michigan, New York, and other states where Onions are grown extensively and the soils have the appearance of pulverized peat bogs. These produce large crops annually without the use of fertilizers, but in certain seasons the bulbs are inclined to be soft with many big necks and scallions, valuable only for immediate use with a trade that does not demand high qualities.

Do not attempt to grow large fields of Onions until the soil has been prepared by liberal fertilizing, and a thorough weed killing process. This will insure large yields and eliminate much of the expense required where the land is foul and poor. Good soil is an important item, but, in addition, the grower must be fully prepared to do his part by intelligent labor. The beginner will do well to gradually grow into the business while testing the possibilities of the soil for producing big yields of superior quality. Use the experience of others. Visit growers who succeed and learn the secret of their success.

\section{PREPARATION OF THE SOIL.}

The yield and quality of a crop of Onions depends Iargely on the manner in which the soil is prepared. Land that 
has been carelessly or hastily prepared rarely produces a yield that is satisfactory to the grower.

For Onions grown from seed it is essential that the ground be fine and loose, and all surface stones and litter removed. The young plants are surface seeders. They camnot thrive if the soil is too dry or unless there is plenty of available plant food present.

The expense of taking care of the crop cluring the growing season may be greatly reduced where the seed bed has been prepared with intelligent care. Do this regardless of the time employed and use a variety of the best tillage implements. Fall plowing is considered much more desirable for Onions than when such work is done in the spring because the soil is exposed during the winter to alternate freezing and thawing which always liberates, or unlocks, plant food and at the same time usually improves its physical condition. This is particularly true in all parts of the Northwest where no loss of fertility occurs from leaching due to winter rains.

\section{SPRING WORK.}

The spring preparation should begin as soon as the soil is sufficiently dry to be worked with a light, fine tooth harrow. Keep the harrow going every day. This should be supplemented with a disk, run shallow, as soon as the surface is made fine and dry with the harrow and by exposure to the sun. The disk should be lapped one-half its width to avoid ridging the ground. Follow immediately with the harrow so that no clods shall form because, if allowed to dry, they will not be crushed. The roll or plank should follow the harrow to firm and level the soil. This is important because a seed bed for Onions should be even and smooth as well as fine, mellow and firm.

The tillage employed while preparing the seed bed will introduce air into the soil, also warm it and, at the same time, liberate plant food, conserve moisture and increase productiveness. Do not begin sowing the seed until an 
ideal seed bed has been obtained. Roll and harrow and plank until you feel that the soil cannot be improved by further use of the tillage implements.

In the event of a dry season the intensive preparation may double the yields. This has been demonstrated again and again by growers of large experience.

\section{FERTILIZERS.}

It is essential that the reader should appreciate the necessity of having the land rich in decaying vegetable matter and available plant food for profitable crops of Onions.

These should be present in abundance before the field is used for the bulbs because they require much to secure large yields. Fresh stable manure and barnyard litters are entirely out of place on the Onion field. They are usually loaded with weed seeds and will interfere very much with tillage, which must be continued during the entire growing season with hand implements. Compost heaps will destroy the weed seeds and put the manures in such condition that they will readily mix with the soil. Manure from sheep sheds or pig pens applied with a spreader before the ground is plowed in the fall makes excellent fertilizer for Onions because it is usually comparatively free from litter and foul seeds. Poultry droppings and wood ashes used for top dressing and applied to the soil before planting, or soon after, will largely increase the yield.

Many of the commercial fertilizers on the market, especially those containing nitrogen, potash and phosphoric acid in an available form, are also highly beneficial and profitable for the Onion fields. These are offered for sale by seedsmen who send them out with the percentage of each of the elements named plainly printed on the sacks which contain 100 pounds each. These chemical fertilizers should be applied, for best results, in small quantities at frequent intervals during the growing season. 


\section{FOOD REQUIREMENTS.}

An analysis of the bulbs shows that a yield of 800 bushels of Onions per acre (44,800 pounds) removes from the soil about 60 pounds of nitrogen, 20 pounds of phosphoric acid and 50 pounds of potash with other solids. This demonstrates that Onions do take large quantities of the fertilizer named from the soil, which must be replaced to insure profitable yields with continued croppings.

\section{CLOVER.}

Clover growing will restore the nitrogen, also the potash and phosphoric acid, in limited quantities, the first named coming from the air, and the others from the sub-soils where these elements accumulate from leaching and thus are beyond the reach of ordinary plants which root near the surface. From 200 to 500 pounds of a chemical fertilizer per acre, applied as suggested on lands where clover has been grown, is usually sufficient. Wood ashes are worth one dollar per barrel when applied to the Onion field. This is due to their large content of potash, also to the mechanical effort in making the soil loose and friable. Wood ashes also aid, in a measure, the control of insect pests. It is said on good authority that air-slaked lime applied occasionally to the growing crop of Onions is a profitable investment, because it corrects acidity in the soil and has a tendency to keep the plants healthy where blight prevails. With an abundant supply of compost, supplemented by the use of store fertilizers and intensive tillage, fields prepared for Onion growing may be profitably cropped to that vegetable for many years.

\section{TILLAGE AND SEEDING IMPLEMENTS.}

Many Onion growers do not fully appreciate the value of a good assortment of labor saving implements. The expense for manual labor to grow an acre of any root crop is an item that often leaves no profit. This was especially 
true years ago, of sugar beets, when the crop was managed by hand. But with the introduction of seeders and tillage implements, drawn by horses, the industry is now very attractive to the American farmer. Onions yield several times as much money per acre as sugar beets and, where an assortment of the best labor saving implements are used, the cost of production should be about equal.

\section{HARROWS.}

A disk and smoothing harrow, and also a roller and planker are indispensable in preparing the field. Combined cutaways, harrows, clod crushers and levelers are on the market; these also do most excellent work in preparing a seed bed for Onions. The writer does not hesitate to recommend them after careful trials in the field. Bear in mind that the soil for Onions must be firm as well as fine and mellow. Great care should be exercised in the matter of handling the soil so that it does not bake or form a crust on the surface in case of extreme changes in the weather. The grower who wishes to malie Onions a specialty cannot afford to use a combined seeder and cultivator, because this is too heavy for the operator to handle day after lay. The expense of two separate machines is only a trifle in excess of the combined seeder and cultivator; which is most valuable for the small garden.

\section{HOE.}

The wheel hoe has a variety of attachments which includes a rake, steel points, clod crushers, knives, etc. Each machine should be ordered complete with all of the attachments. There are also a variety of hand weeders which will save much finger work; time is almost wasted in pulling weeds where the hand weeders are available. Their cost is hardly worth mentioning when compared with the effective work accomplished with the best weeders. Consult the various seedsmen's catalogs for cuts and descrip- 
tions of the labor saving garden tools we mention. They will destroy weeds by the dozen with a single stroke of the hand where only one is pulled with the fingers.

\section{SEED SELECTION.}

This is, by far, the most important problem the grower of Onions has to solve. He is often tempted to purchase seed of questionable origin and uncertain vitality because it is cheap. The difference between the cost of cheap seed and the best quality obtainable is so small when compared to the cost of producing the crop that it would be money wasted to sow the poorer seeds even if they cost nothing. The saving would not exceed five dollars per acre; the loss in yield alone, may represent hundreds of bushels. The quality of a crop of Onions grown from selected seed stock may sell for 25 cents a bushel more than a mixed, ill shaped lot. This would represent $\$ 100$ per acre on a yield of 400 bushels. It sometimes happens that inferior lots of Onions are not salable at any price, while good firm stock of uniform shape and color sells at a handsome profit. Onion seed more than one year old is usually of low vitality and may not grow in the field where ordinary tests for germination were satisfactory. We cannot offer a single excuse for sowing cheap seed, especially for a crop that represents so large an investment of time and money to produce it.

Good Onion seed must be grown from very carefully selected bulbs. The selection should discard everything

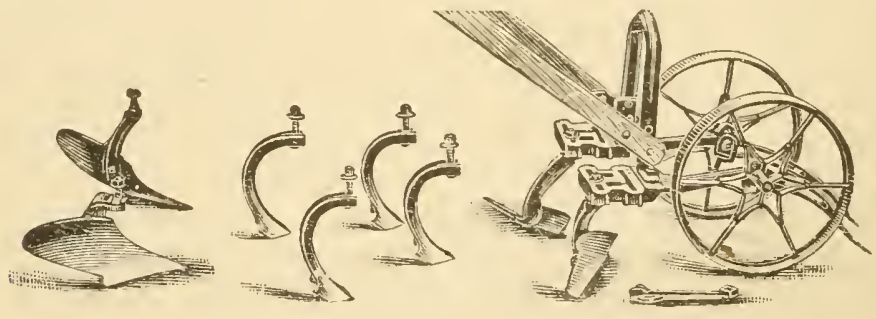

A Good Hand Cultivator. 
that is not true to type in color and shape, and perfectly matured. "Big necks," "scallions" and soft stock are produced in a measure by planting seed grown from that kind of bulbs. "Like produces like," is especially true of seed Onions.

\section{METHODS OF SEEDING.}

Bear in mind the folly of sowing Onion seed in soil that has not been put in ideal condition for the growing crop. Days or even weeks spent in preparation may add largely to yields and will reduce to the minimum the expense of care in the way of cultivation and weeding. Use the best force-feed garden drill obtainable. Test the accuracy of the drill's feed on a floor and carefully note the quantity of seed distributed. This should represent fully twice as many seeds as the grower would require if each one made a matured plant. The seedlings are so delicate that many will fail and fall out by the way in spite of good care. Three pounds of seed per acre is sufficient for a crop of the large varieties. However, four to six pounds are generally planted, especially for small, early stock, where Onion maggots prevail or there is a demand for Bunching Onions.

The seed may be sown thick in the home garden and as the young plants begin to crowd they should be thinned. Plants taken out in the second or third thinning may be used on the table.

The field should be so smooth and the soil so fine that the seed may be covered very evenly with not to exceed one inch of earth. Deep planting is often responsible for crop failures, especially where the soil is inclined to bake or form a crust after heavy rains. The distance between the rows will depend somewhat on the variety, available land, its value, etc. We believe it is a mistake to be stingy with the land and plant too closely. The rows should be straight (for reasons hereafter made plain) and be at least 15 inches apart, and possibly more for the 
larger varieties. These should run north and south, if possible, to admit sunshine to the soil which will hasten maturity and improve the general condition of the crop. Fifteen to twenty seeds per foot should insure a good even stand, provided the germination before sowing was satisfactory. The addition of a small quantity of radish seed will make it possible to start the cultivator in a few days after planting because they come up quickly and plainly define the rows which is not true of the young Onions. Good seed sown in freshly prepared soil which has been well firmed should germinate and grow quickly.

\section{SOW EARLY.}

Early sowed Onion fields always produce the most satisfactory yields; late plantings are usually failures. Do not delay the work of seeding a single minute after the ground has been put in proper condition. Delays are dangerous, especially when planting Onion seed in a soil that is inclined to dry quickly. Everything should be in readiness, the seed, the seeder and the man to operate it. In some instances it is wise to keep the roller and harrow moving just in advance of the garden drill.

\section{THE NEW ONION CULTURE.}

It has been known for many years that seedling Onions can be successfully as well as profitably transplanted. This has been done to a considerable extent where the plants were thin in the rows and an effort to replant would result in failure, which is usually the case when plantings are made after the cool, moist spring weather is past.

The new Onion culture consists in raising Onions by growing seedlings in beds and transplanting them to the open. This method is particularly suited to Onions of the large Spanish type, such as the Prize Taker. The plants should be started under glass, preferably in the greenhouse during February or March. Sow the seed in drills 
$1 \frac{1}{2}$ inches apart, using about an ounce of seed for tell square feet of bed surface. The soil should be sandy and rich. The plants should be kept growing rapidly and as soon as the patch outdoors can be properly prepared in the spring, set the seedlings in rows 14 inches apart and 3 to 4 inches apart in a row. Where green or bunching Onions are grown in this way they can be set more closely, say, 2 inches apart.

There are commercial growers who believe the expense of transplanting is fully offset by the saving in seed, the increased size and yield of the Onions, the certainty of controlling weeds and maturing the crop.

Experiments at State Trial Stations and in market gardens demonstrate that the yield of transplanted Onions, regardless of variety, is nearly fifty per cent greater than by sowing the seed in the open field. In some instances the increase in yield was fully 100 per cent greater.

The roots will be more or less pruned in pulling and the tops should be cut back about one-half of their length. Three active boys make a good transplanting crew, one to make the holes for the seedling with a dibble, one to handle the plants and the other to set them. About 150,000 plants are required to set an acre.

We do not recommend the system, except when the grower wishes to produce extra large Onions for exhibition purposes or is growing them in the South for a very early Northern market. We refer people who are interested and wish information in detail, to publications now obtainable on the subject of "The New Onion Culture."

\section{CULTIVATION AND WEEDING.}

The cultivator should be started immediately after planting. The wheel, on a press drill, will plainly define the rows so that the tillage implements, carefully handled, will not disturb the seed. Cultivation is employed to conserve soil moisture, to liberate plant food, to admit air and incidentally to destroy weeds. Anticipate the coming of the 
weeds and do not allow them to see daylight. Keep the cultivators busy every day, especially after rains to avoid the crusting and baking of the soil. Use the horizontal cutting attachments in the beginning so adjusted that the earth will be slightly moved toward the plants, which will bury many of the tiny weeds and thus save the expense. of finger pulling. As the plants increase in size more eartl may be worked among them.

Use the double wheel hoe which will straddle the rows, and, in the hands of an experienced operator, destroy all weeds on either side of the line of plants provided the rows are as straight as a line. Great care should be exercised in this matter while sowing the seed because short crooks in the rows will make cultivation a slow process and will result in destroying many Onion plants in spite of the painstaking care of the "man behind the hoe.". Active, careful boys, equipped with hand weeders, should follow the cultivators very closely. They must be instructed to-save every Onion and destroy every weed in the rows assigned to each. Pay them by the row rather than day wages. Select one of the most dependable in the bunch for a foreman. The experienced weeder will clean two or three times as many rows in a day as a beginner in the business, hence, the equity of paying by the row.

The boys should be supplied with knee pads covered with leather which will greatly reduce the "wear and tear" on the boys and their pants. The boys should straddle the rows while working to the best advantage, and, with their hand weeders move the earth from the plants, cutting deep so that the grass and weeds may be severed below the crown, otherwise they will sprout and keep coming. Follow the hand weeders in a few hours with the wheel hoe, which will again bank the growing Onions for support.

\section{THINNING.}

Begin thinning as soon as bunching stock can be taken from the rows. Onions should not be hilled like potatoes 
but need a slight support of earth until firmly rooted and the bulbs begin to form, when exposure to the sun and air develops color and firmness; very desirable qualities and much appreciated in the best markets. Deep tillage and severe root pruning always delay maturity and frequently are the cause of soft, green stock at harvest time where the crop would have ripened early and soundly had the roots not been disturbed during the latter part of the growing season. Do not allow a weed to ripen its seed on the Onion field that is devoted for years to such a crop.

Sometimes Onions on rich new land and peaty soils will not ripen in time to cure the crop before freezing weather. Rolling such fields with a barrel, thus breaking the tops, has been recommended as a means of checking growth and hastening maturity. This "killing" process will make the bulbs salable for immediate use, but they will be entirely unfit for winter storage.

The single wheel hoe must be used frequently to conserve soil moisture in the event of droughty weather.

\section{SCALLIONS OR BIG NECKS.}

It sometimes happens that the Onion grower finds a large number of bulbs in his field which have thick necks, being soft, and will not ripen. This may be the result of sowing inferior seed. Sometimes unfavorable conditions of the weather and soil cause the same trouble, especially soil that is cold and wet.

\section{HARVESTING.}

The Onion harvest should begin very soon after the tops fall down and become dry or thoroughly wilted. If allowed to remain in the ground during the wet weather, after the bulbs are ripe, they are quite sure to begin a new growth of root and top which would greatly injure their keeping qualities. Onions may be pulled as soon as the necks wilt and turn yellow. They should then be placed, not thrown, 
into windrows where it will take a week or ten days of exposure to the sun and air to thoroughly cure them. Fully ripe stock will cure in much less time.

Some growers prefer to top their crop of Onions before they are pulled. This method is recommended where the tops are dry and the crop will go to market from the field. Sheep shears are a clesirable implement for the purpose. Another way is to use a thin sharp knife, taking the dry tops with one hand and cutting away from the person. Be careful not to tear the skin down the side. If the tops are left too long it will give them a neglected appearance, and if too short, there is danger of causing the Onions to rot in the tops because of bruising, or from water reaching the inside of the bulb, and thus ruin their keeping qualities. At least one inch of the top should remain on the bulb. Experienced growers have demonstrated that the tops, when attached to the Onions after they are harvested, greatly reduce damage from bruising while they are being handled. The writer is acquainted with growers of large experience who do not top their Onions until they go into the sacks for shipment. An easy and quick method of harvesting a crop of Onions is to lift them with the cultivator steel points or plow and afterward gather them into windrows with a wood-tooth rake. They may be pulled with such a rake as mentioned, provided the soil is loose and mellow. However, it is advisable to first lift them as suggested to save all risk of injury to the crop. White Onions are inclined to sun burn when allowed to remain on the ground for several days. Curing sheds with well ventilated sides and a good roof make a profitable investment for the grower. Small heaps slightly covered with straw will afford sun protection while curing in the field.

\section{MARKETING THE CROP.}

This is a business proposition and should be carefully considered from that point of view by the grower long before the crop is liarvested. The beginner usually acts 
wisely who markets his crop of Onions as soon as possible after they are grown. This safely converts a perishable product into cash which will relieve the producer from further expense, shrinkage in weights, worry, etc., while he enjoys the company of his hard earned dollars. The price of Onions is quite as uncertain as their keeping qualities. They are frequently worth one dollar per bushel in the spring and sometimes must go to the dump because of overstocked markets. The expense of storage during the entire winter, including shrinkage, is often equal to the cost of production. The commission merchant is naturally a speculator, and, being supplied with well equipped cold storage buildings, is entitled to all he can make on the business. However, there are experienced growers who are prepared with crates and buildings suitable for holding their crop until early shipnents are in the hands of consumers and the markets comparatively bare. They usually profit by the risk, provided the marliets come their way and shipments are made in a satisfactory manner. Onions should be carefully topped, graded and have all litter removed before they are placed on sale.

\section{THE GRADER.}

A large tubular grader is an excellent implement for that purpose. This is a drum about two feet in diameter and six feet long, covered with wire screen having $1 \times 1$ inch mesh wire in one-half of its length and $2 \times 2$ inch mesh for the other half. A rod through the center with a crank attached to one end will revolve the sieve drum which must be supported in a. frame one end being considerably higher than the other. This adjustment will carry the Onions along the cylinder from end to end and grade them as they pass through the meshes and out into baskets below.

\section{SORTER.}

A slatted sorter does very satisfactory work but soon fills with the bulbs-which is not the case with the re- 
volving drum. It pays to carefully grade and sort Onions before selling. The standard package for Onions on the market is a burlap sack that will contain, when sewed, just one hundred pounds of the bulbs. The expense of these, and the filling, is small but it settles the question of weights and controversies that frequently arise concerning shortage, shrinkage, etc. Do not attempt to ship Onions in bulk because of the damage from bruising that is quite sure to occur from careless handling. Sell bunching stock while thinning and thus secure an additional income to pay the boys who do the weeding. Small bulbs up to one inch in diameter may be sold for sets and pickling stock. The scallions and thick necks should be sold for immediate use to the home trade. Make the price so low that they will move quickly. If the grower is located near a large city it is usually advisable to turn his second grade stock into money through peddlers who have established a trade for such goods and a reputation that no grower cares to possess. Insist on having buyers inspect and accept your Onions before they are moved from the loading station. This precaution saved the writer from a loss of more than $\$ 2,000$ on a single shipment of Onions which he made when a "boy" in the business. They were sold to a city commission merchant who furnished a man to help sack and load them. On account of an unfavorable season to soundly mature the crop and hot weather while the Onions were in transit they heated and spoiled. The shipper rather than the grower bore the loss because he had previously accepted the stock.

\section{WEIGHT OF ONIONS.}

This fragrant bulb is now quoted and sold by the hundred weight rather than by the bushel. There is a wide difference in the number of pounds required for a bushel by the various states. Fifty-seven pounds is the maximum and is regarded the legal weight by several states; however, a number make fifty-two pounds a legal bushel. 
There are several states that do not establish a legal weight for a bushel of Onions-New York, Pennsylvania and others are in the list. Readers will readily understand the wisdom of a united effort to get out of the old rut of selling Onions by the bushel.

\section{STORING-FALL AND WINTER.}

The keeping qualities of Onions are much improved when they are handled in the field and stored in flat crates or slatted boxes that will hold one or two bushels of bulbs. They may be stacked on the field after a few days' exposure to the sun. When under cover of boards or tar paper the Onions will keep safely until cold weather. Great care must be used in protecting Onions against frosty nights when they are curing in the field. The writer recalls instances where growers have lost an entire crop from the effects of a severe frost while the bulbs were in the windrows. In the event of a prospective frost the Onions should be bunched and covered with straw or crated and stacked for protection. The keeping quality of the bulbs is always more or less injured from a frosty night followed by a bright, warm sunshine. This does not contradict in any measure the fact that Onions may be safely wintered by freezing them solidly while stored in a place where they will not thaw out until spring. A covering of a foot or two of hay will aid very much in keeping the Onions from thawing in the event of warm days during the time they are in storage.

\section{PITTING.}

In some sections Onions are pitted for the winter on a soil that is well drained and'so located that the pits will be protected from the sun-the north side of a hill or hedge is desirable. Make long, narrow, conical heaps which should rest on clean dry straw. Cover the Onions, which must be sound and dry, with slough hay or straw 
and finish with sufficient earth to shed water. Make this smooth and firm by patting it down with a shovel. When the Onions are solidly frozen an additional covering of straw will hold the frost until spring. Do not attempt to move or handle Onions when frozen because it is quite sure to hasten decay and may ruin them for the market. Dry, frost-proof storage is always the most desirable for Onions during the winter.

\section{STORE HOUSE.}

A building having double walls which are papered on either side is usually frost-proof, however, it is advisable to have a stove in a pit or basement underneath to use in the event of severe weather. The heat should circulate between the walls through openings in the floor between the studding and enter the storage room below the ceiling, which should also be papered and covered with sawdust to retain heat and absorb moisture. The building must be provided with ventilators and double windows. Do not place crates or sacks in contact with the walls because they are quite sure to be damp and cold. Do not under any circumstances place Onions in frost-proof storage for the winter until they are thoroughly cured, bone dry, and perfectly dormant in root and top. Discard all bruised and soft stock as well as everything that shows live roots or a green open crown. The shallow, flat crate made from lath with ends and center piece 2 feet long, cut from 1x 4 inch boards, will hold one hundred pounds of Onions. When stacked with spaces between the ends for the circulation of air the Onions will keep until warm weather in splendid condition provided the temperature in the room is kept just above the freezing point. Heat or moisture will cause them to grow. Onions stored in a damp cellar are quite sure to sprout before spring.

\section{SHIPPING.}

Onions are a very perishable product, especially when sacked and stored in a box car which, without ventilation, 
may remain on track for weeks before the stock is unloaded. Don't take any such risks. Order ventilated vegetable cars for early shipments and refrigerators for cold weather. Do not allow the men, while loading, to travel over the filled sacks, because it will greatly injure their keeping qualities. Handle with care every time they are moved.

\section{WARM CAR ESSENTIAL.}

Warm the inside of cars, in winter, with a stove before loading. The heat should be continued until the walls and packing are warmed. Bed the sides of the car with straw and build a false bottom on which the sacks will rest. This should also be supplied with at least six inches of straw to make it frost proof. Onions thus protected in well constructed refrigerator cars will ship safely during the winter months. It is always wise to send a man with cars in severe weather to see that the contents are not allowed to freeze while in transit and deliver the shipment to the purchaser. There are commission merchants who quote attractive prices to growers, a handsome premium above market values, and always report short weights, frosted or lieated stock, etc.

In some instances they do not even report on the shipment but steal the whole bunch. Don't consign to strangers. Sell and insist on payment in advance of the shipment.

\section{VARIETIES.}

For commercial purposes the Onion grower should confine a selection of varieties to a very small number. In fact, we believe he should make a specialty of one only, and build up a trade on that, which in most instances will prove more profitable than several varieties.

The Minnesota Red Globe is now considered the most productive as well as the most profitable variety grown in the Northwest. It is handsome, large and very true to 
type in color and shape. The yield frequently reaches 800 bushels per acre. Growers have reported a crop of more than 300 bushels from one pound of seed.

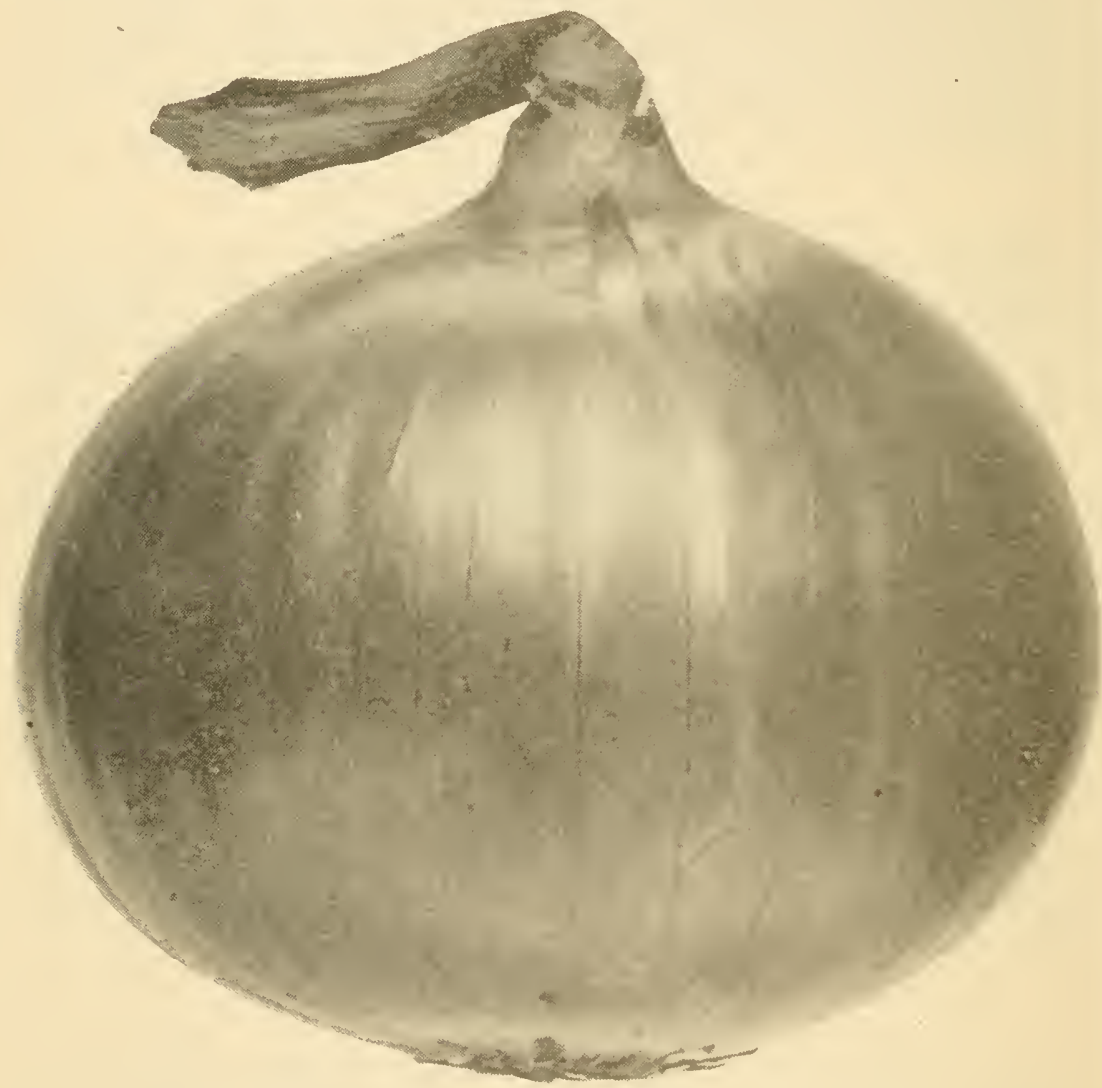

Minnesota Yellow Globe Onion

Its keeping qualities recommend the Minnesota Red Globe for winter storage in the North and for the produce trade in the East and South, where large quantities are shipped every year. The keeping qualities of this Onion are not excelled by any of the American grown varieties. 
The color of Minnesota Red Globe is a deep blood-red, extra dark, while the surface is smooth and glossy. The flesh is white, tinged with light purple, fine grained and unsurpassed in flavor.

A sound, well ripened Onion crop can be put away in the autumn and held for 6 to $\$$ months under suitable conditions with a shrinkage of not much more than a pound per bushel per month. Experienced growers are careful, however, to plant a select strain of seed which has been bred to produce long-keeping, perfectly ripened bulbs.

Minnesota Yellow Globe differs only in color from the Red Globe.

Minnesota White Globe is of the same origin and qualities as the Red and Yellow.

Southport Red Globe. This is an excellent keeper; grows to good size and is very uniform in shape, being nearly round. The color is a dark red with a white, fine grained flesh which recommends it to the trade as well as making it popular with consumers.

Danvers - flat and round-are the most largely grown of the Yellow Onions. They sometimes yield 600 to 800 bushels per acre. However, they are not as hardy as the Reds, hence, usually command higher prices than the Reds on most markets.

White Globe. This is used largely for pickling stock, being sowed thickly; and preferred by critical city trade that takes them on account of their color.

Prize Taker. This variety attains an immense size especially when started from seed under glass during the latter part of the winter and afterward transplanted into rows in the garden. Many growers have adopted this methodcalled the New Onion Culture-believing it to be more profitable in the end than sowing the seed in the open.

Large Red Wethersfield. This is the most extensively grown red variety for the farmer's garden. However, they are no longer popular with the trade.. Red Globes are rapidly displacing the Wethersfield for a commercial crop 
because of their superior keeping-as well as eating-qualities.

\section{ONION SETS.}

Onions are propagated from seed and sets. However, the latter are used only for extra early bunching or table stock. There are only three or four varieties of the sets that are at all popular with market gardeners.

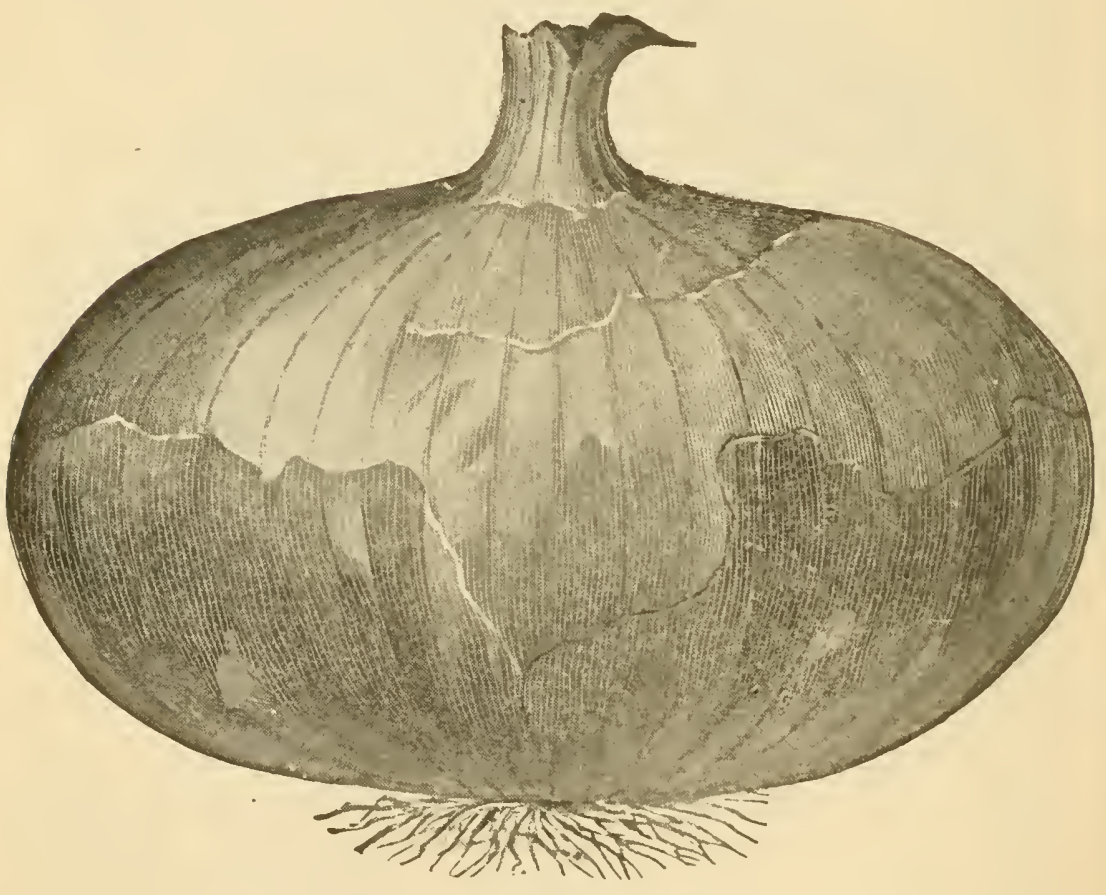

Large Red Wethersfield.

Bottom Sets-Red, Yellow and White. These are produced by sowing seed, early in the spring, at the rate of 75 to 100 pounds per acre. Spreaders are used on the seeders which distribute the seed in drills about 4 inches 
wide and in rows 15 inches apart. The Onions ripen prematurely and should not average more than one-half inch in diameter.

They will not make seed stalks when planted the following year but rapidly increase in size until fully developed. They are usually worth $\$ 3$ to $\$ 5$ per bushel and 10 to 15 bushels are required to plant an acre. In the South they may be planted in the fall. However, this would not be a safe proposition in the North because of our severe winters with the alternate freezing and thawing of the soil during the fall and spring months.

Multipliers, or "Potato Onions"-White and Yellow. These, as the name suggests, multiply in the ground about the parent set. They may be planted in the early spring. Usually about a half dozen of the plants will appear from each set and soon make table or bunching stock.

Prize Taker Onion Sets. These are excellent for use in localities where the season is too short to grow matured bulbs of this variety from seed.

Red Top Sets. Planted to produce both eariy green and large eating onions.

Egyptian Winter or Red Perennial Sets. Entirely distinct from all other varieties of onion; being perfectly hardy everywhere. They should be planted in the fall and left in the ground all winter. These sets never form large bulbs but produce the earliest, small, green onions ready for home or market use weeks ahead of any other sort, unsurpassed in sweetness and tenderness. It is best to replant every autumn and use both roots and tops the following spring. Slight winter protection is required, just a few inches of coarse litter spread on the crowns after the ground freezes, to prevent root heaving. 


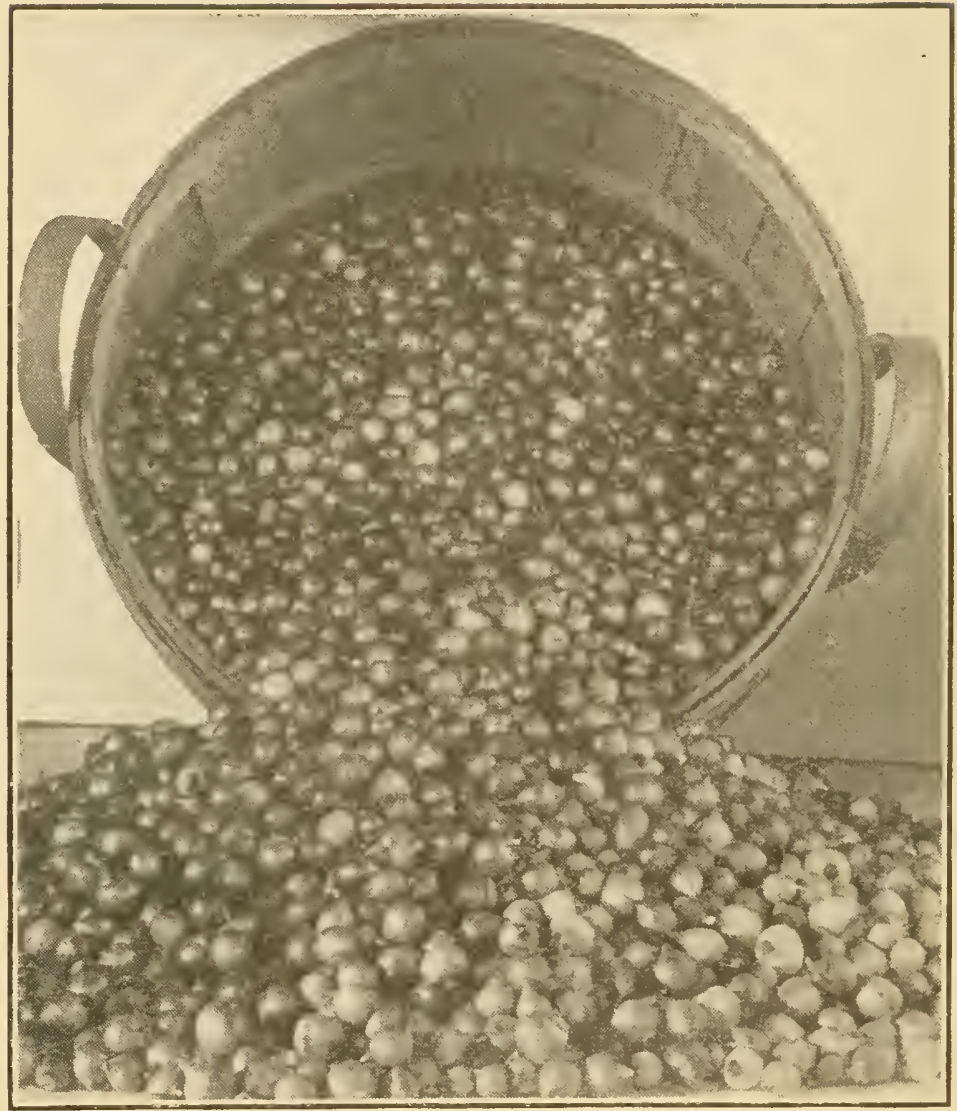

Bottom Onion Sets. 


\section{INDEX.}

Page

Bottom Sets .....22, 24

Clover ...........6 6

Cultivation ..........11

Danvers ...........21

Drainage ...........2

Egyptian Sets ......23

Expense of Crop......1, 4

Hastening Maturity....13

Fertilizing ......... 3

Fertilizers ........5, 6

Freezing .........18

Grader .............15

Harrow ............

Harvesting .........13

Hoe $\ldots \ldots \ldots \ldots \ldots 7,12$

Implements . . . . . . 6

Large Red Weathersfield ..........21

Marketing ........14-15

Minn. Red Globe......19

Multipliers ........23

New Onion Culture....10

Pitting ............17

Potato Onions .......23
Page

Prize Taker .......10, 21 Red Globe ........... 1

Red Perennial Sets.....23 Red Top Sets........23 Scallions ........9, 13 Seed Selection ....... \& Seeding .........9-10 Sets ...........22 Shipping ..........18 Soil ...........2- 4 Sorter ............15 Spring Work ....... 4 Storing .........17-18 Sun Burn ..........14 Thinning ..........12 Topping ...........14 'T ransplanting ....... 10 Value of Crop......... 3 Varieties ............19 Weeders .......... 7 Weight ............16 Weeding ..........11 Winter Sets ........23 


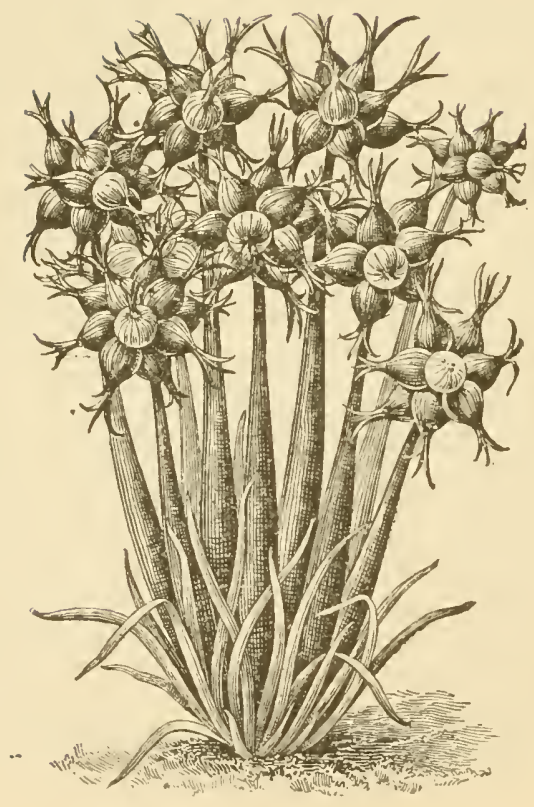

Egyptian Onion Sets. 


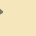




\section{LIBRARY OF BOOKLETS}

\section{How To Obtain Them}

The regular price of these booklets is 10 cents each. Wo will, if requested, send a booklet free with orders for each of the artícles upon which the booklet treats. To those who wish to obtain booklets immediately, wo make the following special offer: We will send any one booklet, postpald, for five cents; any seven for 25 cents, or sixteen postpaid for 50 cents.

If on receipt of the booklets you are not satisfled with the investment, keep the booklets and we will promptly and without question refund the money:

\section{Alfalfa}

Cabbage Growing

Clover

Field Corn

Hand Book for the Garden Insects and Diseases

Lawns

More Pork Profits
Onion Culture

Pastures and Soiling Crops

Potato Culture

Profitable Poultry

Quack Grass and Other Weeds

Root Crops

Silage and Silos

Vine Crops

We ahall add to thls lot from time to time.

NORTHRUP, KING \& CO., Seedsmen, MINNEAPOLIS, MINN. 


\section{LIBRARY OF CONGRESS}

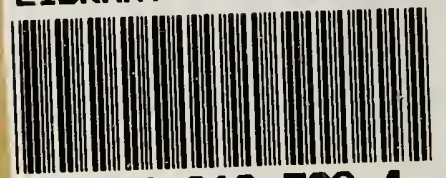

0 0009167924 